\title{
Two-dimensional Periapical, Panoramic Radiography Versus Three-dimensional Cone- beam Computed Tomography in the Detection of Periapical Lesion After Endodontic Treatment: A Systematic Review
}

\author{
Delphine P. Antony ${ }^{1}$, Toby Thomas ${ }^{1}$, MS Nivedhitha ${ }^{1}$ \\ 1. Conservative Dentistry and Endodontics, Saveetha Dental College-Saveetha University, Chennai, IND
}

Corresponding author: Delphine P. Antony, delphy.priscilla@gmail.com

\begin{abstract}
Radiographic imaging is a common resource for endodontic diagnosis, treatment, and prognosis. Twodimensional (2D) periapical and digital panoramic radiographs often showed image distortion; this issue was resolved with the emergence of three-dimensional (3D) cone-beam computed tomography (CBCT). This review examines the accuracy of various radiographic techniques in the assessment of periapical lesion after endodontic treatment. Our goal was to determine whether a $2 \mathrm{D}$ radiograph (periapical and panoramic) is as accurate as a 3D radiograph (i.e., CBCT) in the assessment of periapical lesion after endodontic treatment. We searched the electronic databases Medline and Cochrane and trial registries for ongoing trials. We included both retrospective and prospective studies comparing the efficacy of periapical healing with various radiographic techniques after endodontic treatment. The outcome of interest was the percentage detection of periapical lesions and periapical healing assessment after endodontic treatment. All data were collected using a specially designed extraction form. We assessed the risk of bias in the studies using the Cochrane tool for diagnostic tests (QUADAS). We judged two studies to be at low risk and two to be at moderate risk of bias. Although there was a difference in the percentage detection of periapical healing efficacy by various radiographic techniques, all studies reported that CBCT had higher accuracy in the detection of periapical lesions compared to periapical and panoramic radiography. The next best choice is periapical radiographs, followed by panoramic radiographs as they provide better visualization and accuracy.
\end{abstract}

Categories: Pathology, Radiology, Dentistry

Keywords: periapical, panoramic radiograph, cbct, periapical lesion, endodontic treatment

Received 04/01/2020

Review began 04/08/2020 Review ended 04/11/2020 Published 04/19/2020

(c) Copyright 2020 Antony et al. This is an open access article distributed under the terms of the Creative Commons Attribution License CC-BY 4.0., which permits unrestricted use, distribution, and reproduction in any medium, provided the original author and source are credited.

\section{Introduction And Background}

Apical periodontitis (AP) is an inflammation of the periodontium caused by trauma, irritation, or infection through the root canal, regardless of whether the pulp is vital or non-vital. It represents the main indication for root canal treatment. Most patients with AP are asymptomatic. However, pain, tenderness to biting pressure, percussion, or palpation, as well as swelling are typical clinical expressions of symptomatic AP. The assessment of periapical status through radiographic examination is important because it may help to define treatment needs and relates treatment outcomes to various technical and clinical factors of the endodontic intervention. The radiographic assessment of AP is done using the periapical index (PAI). The PAI represents an ordinal scale of five scores ranging from no disease to severe periodontitis with exacerbating features [1]. The main objectives of endodontic treatment are to retain the normal function of the treated tooth and to prevent or heal AP [2,3]. A radiological examination is a major tool in dentistry for a thorough exploration that helps to achieve the goals mentioned above.

There are several types of radiographic interventions. Periapical radiography offers important evidence on the progression, regression, and persistence of AP [4]. This can confirm the number of roots and their configuration together with the presence or absence of periapical lesions and their locations. It corresponds to a two-dimensional (2D) aspect of a three-dimensional (3D) structure [5]. Panoramic radiography is a curved plane tomographic radiographic technique that obtains an image by synchronous rotation of the $\mathrm{X}$ ray source and image receptor around the stationary patient. It helps in identifying anatomical landmarks, pathosis in maxilla, mandible and maxillary sinus [6]. Cone-beam computed tomography (CBCT) has been specifically designed to produce 3D images of the maxillofacial skeleton. CBCT is indicated for the diagnosis of pathosis of endodontic and non-endodontic origins, assessment of root canal morphology, evaluation of root and alveolar fractures, analysis of external and internal root resorption, and pre-surgical planning in root-end surgeries [7].

Periapical periodontitis in periapical radiography is represented as a reduction in mineral density that is represented as radiolucency. Lesions confined within the cancellous bone cannot be detected, whereas 
lesions with buccal and lingual cortical involvement produce distinct radiographic areas of rarefaction. To be visible radiographically, a periapical radiolucency should reach nearly $30-50 \%$ of bone mineral loss [8]. Panoramic imaging is similar to periapical radiographs but more useful for diagnostic problems requiring broad coverage of the jaws like large lesions [9]. The specific endodontic applications of CBCT involve the change from analog to digital imaging and advances in imaging theory and volume-acquisition data, enabling detailed 3D imaging. Investigations have demonstrated that a cyst could be distinguished from periapical granulomas by CBCT because it shows a marked difference in density between the content of the cyst cavity and granulomatous tissue, thus favoring a noninvasive diagnosis $[10,11]$.

This review was conducted because radiographic imaging plays a vital role in the diagnosis, treatment plan, and prognosis of endodontic treatment of teeth with periapical periodontitis. If the 2D radiograph is shown to be as accurate as CBCT in the detection of periapical healing after endodontic treatment, it could be costeffective and cost-beneficial for both the patient and dentist. The objective of the review is to determine whether periapical and panoramic radiograph is as accurate as CBCT in the detection of periapical lesion healing after endodontic treatment.

\section{Review}

We included retrospective and prospective studies that compared periapical radiograph, panoramic radiograph, and CBCT. We excluded case reports, case series, animal studies, and in-vitro studies that measured the same outcomes of interest. Participants were aged 16 years or older who required root canal treatment for AP or apical lesions. All participants had at least one tooth (single-rooted or multi-rooted) with a history of secondary and primary endodontic infections as confirmed by a clinical examination.

The index tests were performed with conventional periapical and panoramic radiographs. Conventional radiographs used in all studies were obtained by paralleling technique and a horizontal angle difference of about 10 degrees. The films were processed in an automatic processor and developed by using standardized methods. The target conditions were AP and periapical lesions. The reference standard was 3D Accuitomo XYZ Slice View CBCT (J. Morita Corp., Osaka, Japan). The PAI scoring system was used in most of the included studies for radiographic assessment of AP by conventional radiography and CBCT.

For our search methods, we developed detailed strategies for each database to identify studies for this review. These were based on the search strategy developed for Medline Ovid and used a combination of controlled vocabulary and free text terms (a table with details of the search methods is provided in the Appendices). Our electronic searches were conducted on Medline and Cochrane. We did not place any restrictions on the language or date of publication when searching the electronic databases. For other resources, we searched trial registries for ongoing studies using the World Health Organization International Clinical Trials Registry Platform. Additionally, we manually searched, with the assistance of a librarian, the following journals: Journal of Endodontics; International Endodontic Journal; Oral Surgery, Oral Medicine, Oral Pathology, and Oral Radiology; and Endodontology.

The studies obtained by the search were assessed by the authors to determine whether studies met the selection criteria. All retrospective and prospective human in-vivo studies that compared periapical radiograph, panoramic radiograph, and CBCT for periapical periodontitis after endodontic treatment were included. Case reports, case series, animal studies, and in-vitro studies that measured the same outcomes of interest were excluded. We resolved any disagreements by discussion. The review authors independently examined the title and abstract of each article identified by the search strategy. Whenever studies appeared to meet the inclusion criteria for this review or where there was insufficient data in the title and abstract to make a clear decision, we obtained the full report. We also recorded the number of studies rejected at this or subsequent stages. A flowchart that summarizes the results of the search is given below (Figure 1). 


\section{Cureus}

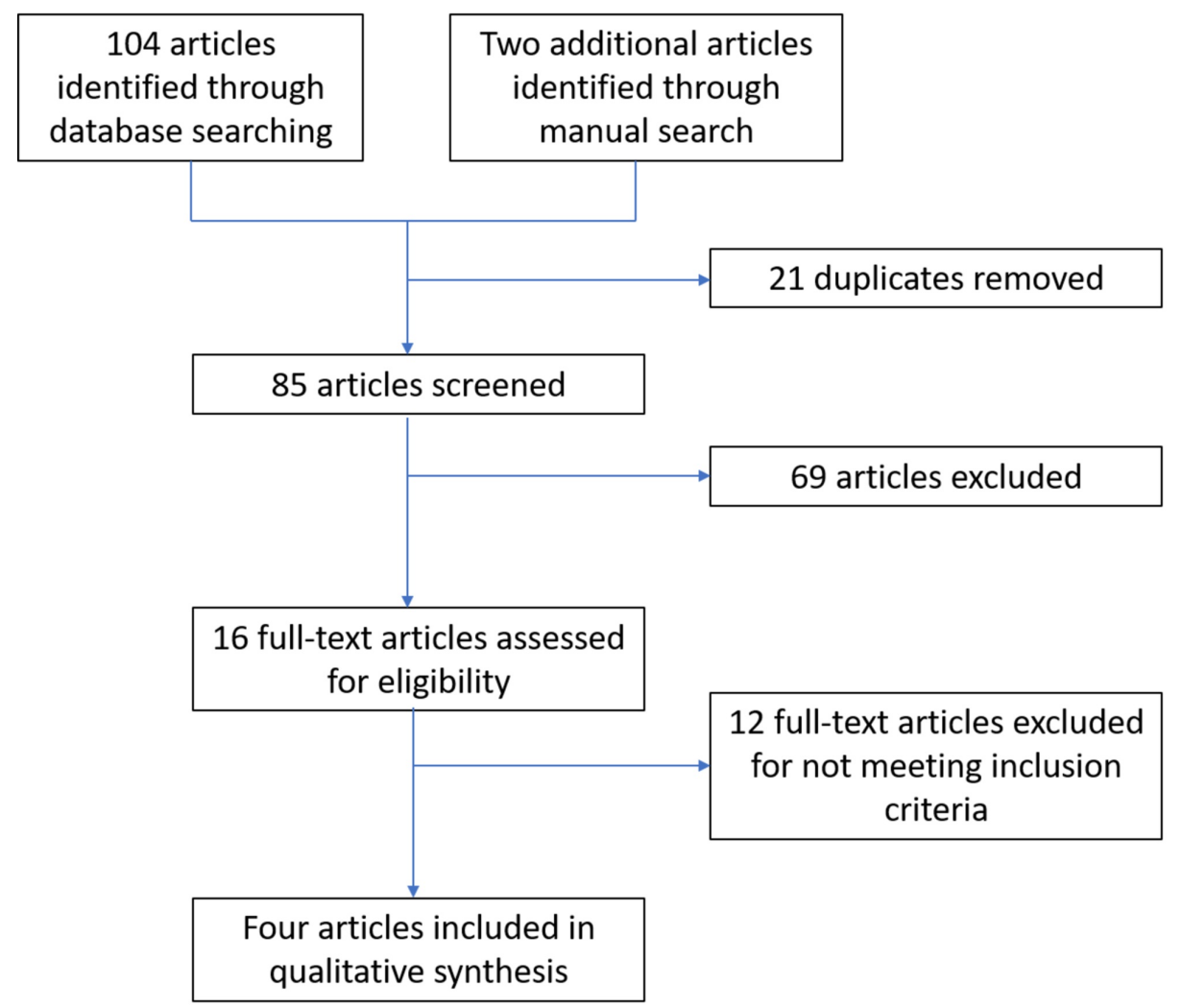

FIGURE 1: Study flowchart

Review authors independently extracted data using a specially designed data extraction form and entered them into a spreadsheet. For each study, we recorded the following data: year of publication; country of origin; study design; the number of participants included; the number of teeth evaluated; demographic details of the participants; study set-up; techniques used for index test and reference test; details of the outcomes reported, including method of assessment; and time(s) assessed.

We performed an assessment of methodological quality. The review authors independently assessed the risk of bias of the included studies, and any disagreement was resolved through discussion and consensus. We used the recommended approach for assessing the risk of bias using QUADAS: a 14-item tool for the quality assessment of studies of diagnostic accuracy included in systematic reviews [12]. We addressed four domains for risk of bias and three domains for applicability of concerns, including patient selection, index test, reference standard, flow, and timing. Within each entry, we described what was reported to have happened in the study and monitored for insufficient detail to support a judgment about the risk of bias. We then assigned a judgment relating to the risk of bias for that entry of either low, high, or unclear. After considering the additional information provided by the authors, we summarized the risk of bias in the studies as one of the following: low risk of bias - a low risk of bias for all key domains; unclear risk of bias an unclear risk of bias for one or more key domains; high risk of bias - a high risk of bias for one or more key domains.

We used the recommended approach for assessing the risk of bias using QUADAS. We completed a risk of bias table for each included study and presented graphically by study and by domain across all studies (Figures 2, 3) [13-16]. Two studies had a moderate risk of bias, whereas two studies had a low risk of bias. 


\section{Cureus}

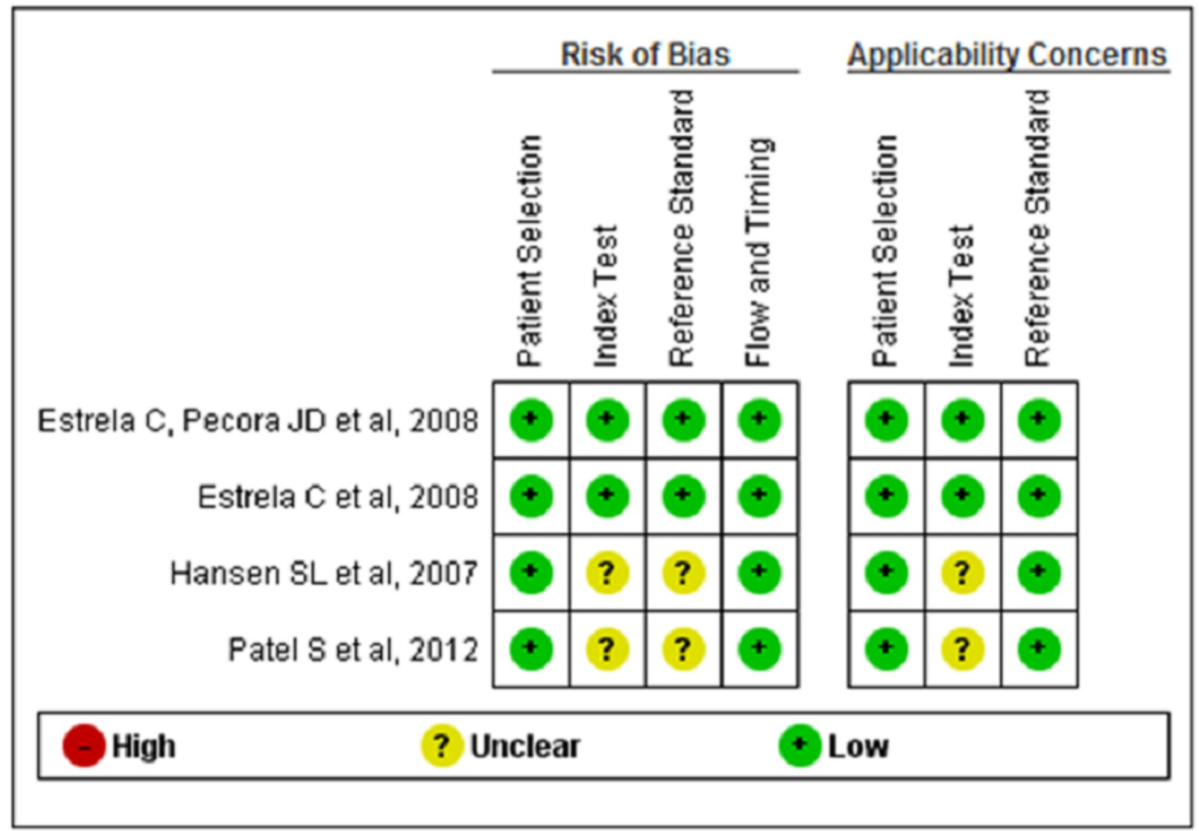

FIGURE 2: Risk of bias and applicability concerns summary: review authors' judgments about each domain for each of the included studies

\begin{tabular}{|c|c|c|c|c|c|c|c|c|c|c|}
\hline \multirow{6}{*}{$\begin{array}{r}\text { Patient Selection } \\
\text { Index Test } \\
\text { Reference Standard } \\
\text { Flow and Timing }\end{array}$} & \multicolumn{5}{|c|}{ 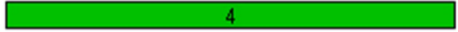 } & \multicolumn{5}{|c|}{4} \\
\hline & & 2 & & \multicolumn{2}{|l|}{2} & & 2 & 1 & \multicolumn{2}{|l|}{2} \\
\hline & & 2 & 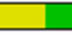 & \multicolumn{2}{|l|}{2} & \multicolumn{5}{|c|}{4} \\
\hline & \multicolumn{5}{|c|}{4} & & & & & \\
\hline & $0 \%$ & $25 \%$ & $50 \%$ & $75 \%$ & $100 \%$ & $0 \%$ & $25 \%$ & $50 \%$ & $75 \%$ & $100 \%$ \\
\hline & \multicolumn{5}{|c|}{ Risk of Bias } & \multicolumn{5}{|c|}{ Applicability Concerns } \\
\hline High & & & $\square$ Unc & & & & Low & & & \\
\hline
\end{tabular}

FIGURE 3: Risk of bias and applicability concerns graph: review authors' judgments about each domain presented as percentages across included studies

\section{Results of the search}

The characteristic of the studies included the following eight entries: study ID, clinical features and settings, participants, study design, target condition, index and comparator test, manufacturer and technical details, and follow-up. This information is presented for each study in Table 1. Similarly, the number of studies excluded with the reason for exclusion is presented in Table 2 .

Characteristics Details

Study ID

Lofthag-Hansen et al. [13]

Patients had at least one tooth with a

history of secondary and primary

Clinical

features and

settings endodontic infections, which is

tender on percussion. Pre-diagnostic Performed

Performed

Performed
Estrela et al. [15]

Patel et al. [16]

Estrela et al. [14]

Root canal treatment was done in a

university clinical set-up 
Participants $\quad 46$ teeth of 36 patients; mean age: 50 years; men: $36.2 \%$, women: $63.8 \%$

A single group with a periapical lesion consecutively enrolled; directly compared pre- and post-periapical radiograph and $\mathrm{CBCT}$; participants identified prospectively and all received both radiographs

\section{Target} condition

Index and comparator test

Manufacturer and technical details
1,508 teeth of 888 patients; mean age: 0 years; men: $41 \%$, women: $59 \%$

A single group with a periapical lesion consecutively enrolled; directly compared pre- and postperiapical radiograph and $\mathrm{CBCT}$; participants identified retrospectively, and all received both radiographs

Periapical lesion due to pulpal pathology

Periapical radiograph and $\mathrm{CBCT}$. Three specialists in oral and maxillofacial radiology analyzed all radiographs together. First, the intraoral ones were evaluated and, after two weeks, all CBCT images. Later, a direct comparison between intraoral radiographs and CBCT images was performed. Kappa value was not mentioned

Periapical radiographs: parallelling technique and horizontal angle difference of 10 degrees using an Oralix DC (Gendex Corporation, Milwaukee, WI) dental X-ray machine at $65 \mathrm{kV}$ and $7.5 \mathrm{~mA}$. Film distance: $22 \mathrm{~cm}$ and exposure time; 0.32-0.5 s with F-speed films (Kodak Insight; Eastman Kodak, Rochester, NY). СBCT operating parameters were 2.0-4.0 mA, $80 \mathrm{kV}$, exposure time: $17.5 \mathrm{~s}$ using sagittal slices $(1 \mathrm{~mm}$ thick). Images analyzed by Dell Workstation PWS 350 and Dell monitor (size 18 inches) (Dell, Round Rock, TX) with Trinitron tube, 1,024 x 768 pixels (Sony, Tokyo, Japan)

\section{Apical periodontitis} Periapical, panoramic radiograph, and CBCT. Three calibrated blinded examiners visualized. The presence of periapical lesion diagnosed by СВСТ considered as the standard reference. Kappa value: 0.89-1.00 for periapical, panoramic radiograph, and $\mathrm{CBCT}$
Periapical radiographs: Max S-1 Xray equipment (J. Morita Corp., Osaka, Japan) with $0.8 \mathrm{~mm} x$ $0.8 \mathrm{~mm}$ tube focal spot and with Kodak Insight film (Eastman Kodak, Rochester, NY) using a parallel technique. CBCT images: 3D Accuitomo XYZ Slice View Tomograph (model MCT-1; J. Morita Corp.) voxel size of $0.125 \times 0.125 \mathrm{x}$ $0.125 \mathrm{~mm}, 12$ or 8 bits. Images examined by 3D Tomo $x$ version 1.0.51. Panoramic radiographs: Veraviewepocs panoramic X-ray unit $\mathrm{mm}$ tube focal spot with Kodak dental films (T-MAT, 15 x 30; Manaus, Brazil) (J. Morita Corp.) with a $0.5 \mathrm{~mm}$ x 0.5

of 596

patients;

mean age:

54 years;

men: $40.4 \%$,

women:

$59.6 \%$

A single group with a periapical lesion consecutively enrolled; directly compared pre- and

Performed post-periapical radiograph and CBCT; participants identified prospectively and all received both radiographs

$$
\begin{aligned}
& \text { Apical Periapical lesion of } \\
& \text { periodontitis inflamed pulpal }
\end{aligned}
$$

\section{Periapical radiographs and CBCT. \\ Three calibrated blinded \\ observers \\ evaluated all digital images by using the CBCT and periapical. Kappa value: $0.86-$ 0.96 for periapical radiograph and CBCT}

\section{Periapical} radiographs and CBCT scans. Two calibrated examiners evaluated all the images. Kappa value: 0.7 for periapical radiograph and 0.9 for CBCT

Periapical radiographs: dental $X$-ray machine (Planmeca Prostyle Intra, Helsinki, Finland) using a digital CCD (Schick Technologies, New York, NY) at $66 \mathrm{kV}$, $7.5 \mathrm{~mA}$, and $0.10 \mathrm{~s}$ Performed using parallel. Smallvolume $\left(40 \mathrm{~mm}^{3}\right)$ CBCT scans (3D Accuitomo F170; J Morita Corp.) at 90 kV, $5.0 \mathrm{~mA}$, and 17.5 $\mathrm{s}$, reformatted $(0.125$ slice intervals and $1.5 \mathrm{~mm}$ slice thickness)

Followed up for one 


\section{Cureus}

Follow-up

No loss to follow-up or missing or uninterpretable test results

\section{TABLE 1: Characteristics of Included studies}

СВСТ: cone-beam computed tomography

\begin{tabular}{|c|c|c|}
\hline Study no. & Author & Reason for exclusion \\
\hline 1 & Abella et al. [17] & No endodontic treatment performed \\
\hline 2 & Kaya [18] & Compared before and after endodontic treatment with no periapical lesion \\
\hline 3 & Gumru [19] & Only a subpopulation was included \\
\hline 4 & Rios-Santos et al. [20] & No endodontic treatment performed \\
\hline 5 & Raghav et al. [21] & No endodontic treatment performed \\
\hline 6 & Levin et al. [22] & Case report \\
\hline 7 & Liang et al. [23] & Preoperative radiographs not taken \\
\hline 8 & Ridao-Sacie et al. [24] & No endodontic treatment performed \\
\hline 9 & Yoshioka et al. [25] & Case report \\
\hline 10 & Delano et al. [26] & Animal study \\
\hline 11 & Molander et al. [27] & Unable to access \\
\hline 12 & Rohlin et al. [28] & Unable to access \\
\hline
\end{tabular}

TABLE 2: Characteristics of excluded studies

Each study evaluated periapical lesions using different methods of evaluation. One study used the PAI based on eight categories qualitatively, which compared 46 teeth of 36 patients and showed that periapical radiograph detected $70 \%$ of the periapical lesions and CBCT detected $91.3 \%$ of the periapical lesions [13]. Another study evaluated the periapical lesions using the PAI scoring system. It reported that periapical radiograph detected $35.3 \%$, panoramic radiograph detected $17.6 \%$, and CBCT detected $63.3 \%$ of the presence of periapical periodontitis [14]. Similarly, another study used a modified PAI scoring system with an additional score of $\mathrm{E}$ (i.e., expansion of periapical cortical bone) and D (i.e., destruction of periapical cortical bone); this study showed that periapical radiograph detected $40 \%$ and $60 \%$ of presence and absence of periapical periodontitis, respectively, compared to CBCT, which detected 61\% and 39\%, respectively [15]. Another study qualitatively evaluated periapical lesion healing based on six categories, which showed that digital periapical radiograph detected $89.6 \%$ and CBCT detected $86.1 \%$ of reduced periapical lesions [16]. Summary results, method of evaluation, and outcomes of each study are provided in Table 3. Summary findings across the studies are presented in Table 4. 


\section{Cureus}

\begin{tabular}{|c|c|c|c|}
\hline Author/year & Method of evaluation & Results & Outcomes \\
\hline $\begin{array}{l}\text { Lofthag- } \\
\text { Hansen et } \\
\text { al./2007 [13] }\end{array}$ & $\begin{array}{l}\text { Number of roots, root canals (unfilled and filled), roots } \\
\text { involved in a lesion, presence of root canal post, periapical } \\
\text { lesion, size of the lesion, the effect on or perforation of the } \\
\text { cortical bone plate, the distance between a lesion and } \\
\text { mandibular canal/maxillary sinus apex and mandibular canal, } \\
\text { expansion of lesion into the maxillary sinus, apical-marginal } \\
\text { communication, and marginal bone level }\end{array}$ & $\begin{array}{l}\text { Periapical radiograph } \\
\text { detected } 69.5 \% \text { and СВСТ } \\
\text { detected } 91.3 \% \text { of periapical } \\
\text { lesion }\end{array}$ & $\begin{array}{l}\text { The detection of } \\
\text { apical periodontitis } \\
\text { was considerably } \\
\text { higher with CBCT } \\
\text { than with periapical } \\
\text { radiography }\end{array}$ \\
\hline $\begin{array}{l}\text { Estrela et } \\
\text { al./2008 [14] }\end{array}$ & $\begin{array}{l}\text { Periapical index: normal periapical structures; small changes } \\
\text { in the bone structure; changes in the bone structure with some } \\
\text { mineral loss; periodontitis with a well-defined radiolucent } \\
\text { area; severe periodontitis with exacerbating features }\end{array}$ & $\begin{array}{l}\text { Panoramic detected } 17.6 \% \\
\text { and } 82.4 \% \text {, periapical } \\
\text { radiograph detected } 35.3 \% \\
\text { and } 64.7 \% \text {, and CBCT } \\
\text { detected } 63.3 \% \text { and } 36.7 \% \\
\text { of presence and absence of } \\
\text { apical periodontitis } \\
\text { respectively }\end{array}$ & $\begin{array}{l}\text { The prevalence of } \\
\text { correct identification } \\
\text { apical periodontitis } \\
\text { was higher with CBCT } \\
\text { in comparison with } \\
\text { periapical and } \\
\text { panoramic } \\
\text { radiographs }\end{array}$ \\
\hline $\begin{array}{l}\text { Estrela et } \\
\text { al./2008 [15] }\end{array}$ & $\begin{array}{l}\text { Intact periapical bone structures; diameter of periapical } \\
\text { radiolucency: } 0.5-1 \mathrm{~mm} \text {; diameter of periapical radiolucency: } \\
1-2 \mathrm{~mm} \text {; diameter of periapical radiolucency: } 2-4 \mathrm{~mm} \text {; } \\
\text { diameter of periapical radiolucency: } 4-8 \mathrm{~mm} \text {; diameter of } \\
\text { periapical radiolucency } 8 \mathrm{~mm} \text {; score }(\mathrm{n}) \text { \# E (expansion of } \\
\text { periapical cortical bone); score ( } \mathrm{n} \text { ) \# D (destruction of } \\
\text { periapical cortical bone) }\end{array}$ & $\begin{array}{l}\text { Periapical radiograph } \\
\text { detected } 39.5 \% \text { and } 60.5 \%, \\
\text { and CBCT detected } 60.9 \% \\
\text { and } 39.1 \% \text { of presence and } \\
\text { absence of apical } \\
\text { periodontitis, respectively }\end{array}$ & $\begin{array}{l}\text { The detection of } \\
\text { apical periodontitis } \\
\text { was considerably } \\
\text { higher with СBCT } \\
\text { than with periapical } \\
\text { radiography }\end{array}$ \\
\hline $\begin{array}{l}\text { Patel et } \\
\text { al./2012 [16] }\end{array}$ & $\begin{array}{l}\text { Based on six categories of periapical changes: new periapical } \\
\text { radiolucency; enlarged periapical radiolucency; unchanged } \\
\text { periapical radiolucency; reduced periapical radiolucency; } \\
\text { resolved periapical radiolucency; unchanged healthy } \\
\text { periapical status }\end{array}$ & $\begin{array}{l}\text { Periapical radiograph } \\
\text { identified } 89.6 \% \text { and } 10.4 \% \text {, } \\
\text { and } \mathrm{CBCT} \text { identified } 86.1 \% \\
\text { and } 13.9 \% \text { of reduced and } \\
\text { unchanged lesions } \\
\text { respectively }\end{array}$ & $\begin{array}{l}\text { Periapical } \\
\text { radiolucency revealed } \\
\text { a } 14 \text {-fold higher } \\
\text { failure rate when } \\
\text { assessed using CBCT } \\
\text { (17.6\%) compared } \\
\text { with periapical } \\
\text { radiographs }(1.3 \%)\end{array}$ \\
\hline
\end{tabular}

TABLE 3: Summary of results of included studies

СВСТ: cone-beam computed tomography

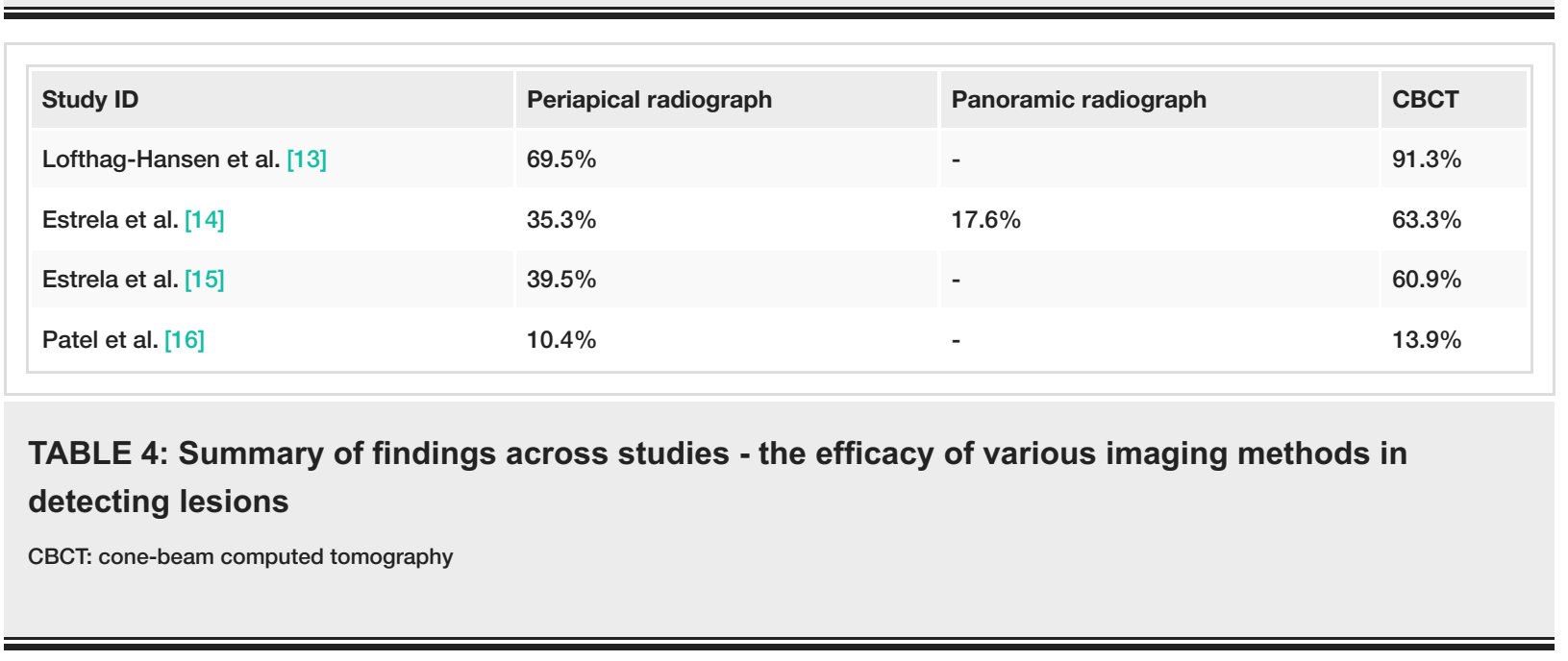

Only one study reported the sensitivity and specificity for periapical and panoramic radiographs by keeping CBCT as the standard reference. The sensitivity for periapical and panoramic radiograph was $55 \%$ and $28 \%$, respectively; specificity and positive predictive values (PPV) ranged from 0.96 to 1.00, and negative predictive values (NPV) ranged from 0.35 to 0.65 . The overall accuracy for periapical and panoramic radiographs was $70 \%$ and $54 \%$, respectively [14]. 


\section{Summary of the main results}

One study examined 36 patients who had undergone endodontic treatment. A total of 46 teeth were included in the study and were subjected to periapical radiography and CBCT. Periapical lesions were detected in the same 32 teeth by periapical radiograph and СBCT. An additional 10 teeth were detected using CBCT. With both techniques analyzed together, all observers agreed that the CBCT images in those 32 cases provided clinically relevant additional information such as better visualization of the anatomy of the roots and root canals, improved understanding of the location of lesions, and the relation of the lesions with the surrounding structures. СBCT detected more lesions compared to periapical radiographs [13].

Another study examined 888 consecutive patients for the detection of periapical lesions using CBCT, periapical radiography, and panoramic radiography after endodontic treatment. Radiographs were taken, and the assessment was based on the PAI. CBCT tended to offer greater scores than periapical and panoramic radiographs. The limitations of conventional radiographs include compression of 3D anatomy into a 2D shadowgraph causing geometric distortion and a high possibility for false-negative diagnosis [14].

An additional study gave a new PAI based on СBCT. This study included 596 patients; all patients had one or more endodontically treated teeth. Periapical radiographs and CBCT images were taken to detect the presence of a periapical lesion. All the images were subjected to the CBCT PAI, which has some advantages for clinical application. The goal of this index is to offer a method based on the interpretation of highresolution images that can provide a more precise measurement of AP extension, minimizing observer interference, and increasing the reliability of research results. CBCT was shown to be more accurate than periapical radiography in the diagnosis of AP [15]. Another study included 99 patients who were assessed one year after endodontic treatment by a single operator that compared periapical radiographs and CBCT. The images were assessed by the PAI using six categories for the detection of periapical lesions. The study revealed lower healed and healing rates for root canal treatment assessed with CBCT than with periapical radiographs [16].

\section{Strengths and weaknesses of the review}

The review included retrospective and prospective studies and excluded case reports, case series, animal studies, in-vitro, and ex-vivo studies. Since human in-vivo studies have been reviewed, there is applicability for clinical practice. We have taken steps to minimize bias in every step of the review. We searched databases and trial registries with no language limitations to identify all the relevant reports. We assessed the methodological quality of included studies using QUADAS, a 14-item tool for the quality assessment of studies of diagnostic accuracy that provides detailed information on the risk of bias and concerns regarding applicability. All included studies had good methodological quality. Though each study evaluated periapical lesion using different methods with different criteria, the detection of presence or absence of periapical lesion was reported in almost all studies with the standard reference being СВСТ. Only one study reported the sensitivity, specificity, PPV, NPV, and accuracy for the periapical and panoramic radiographs [14]. Therefore, no statistical analysis and data synthesis, sensitivity analysis, and investigation of heterogeneity had been performed. This review failed to search other databases such as Excerpta Medica dataBASE (EMBASE) and EBSCO.

The available evidence is from a range of countries and is applicable to patients older than 16 years. Identified studies did not include patients without periapical lesions and endodontic treatments. The results of this review may or may not be generalizable to these groups. All included studies were conducted in university clinics with a single operator, and radiographs were assessed by experts with minimal disagreement. Thus, the generalizability of this review results is possible. Since all included studies reported the manufacturer and technical details for periapical radiograph, panoramic radiograph, and CBCT, there was no limitation for external validity.

\section{Conclusions}

Based on this review, all studies with good quality of evidence demonstrated that CBCT provided better detection of periapical lesions after endodontic treatment, followed by periapical and panoramic radiography. The success of CBCT depends on the familiarity of the practitioner with the technique and the assessment of the images. Thus, a periapical radiograph would be an alternative for CBCT with better visualization and accuracy. In the future, research should be aimed at the better matching of groups and variables such as operator experience and familiarity to validate the findings of the radiographic imaging.

\section{Appendices}




\section{Cureus}

\begin{tabular}{|c|c|c|c|c|}
\hline Search & $\begin{array}{l}\text { Add to } \\
\text { builder }\end{array}$ & Query & $\begin{array}{l}\text { Items } \\
\text { found }\end{array}$ & Time \\
\hline \#1 & Add & Search endodontics & 29,144 & 12:06:05 \\
\hline \#2 & Add & Search apical periodontitis & 4,826 & 12:06:23 \\
\hline \#3 & Add & Search chronic apical periodontitis & 772 & 12:07:08 \\
\hline \#4 & Add & Search periapical periodontitis & 4,355 & 12:07:26 \\
\hline \#5 & Add & Search apical lesion & 1,044 & 12:07:50 \\
\hline$\# 6$ & Add & Search periapical disease & 7,088 & 12:08:12 \\
\hline \#7 & Add & Search root canal therapy & 18,668 & 12:08:25 \\
\hline \#8 & Add & Search root filled teeth & $2,0 / 8$ & 12:09:00 \\
\hline \#9 & Add & Search in vivo & $6,54,476$ & 12:09:10 \\
\hline \#10 & Add & Search periapical radiography & 2,617 & 12:09:32 \\
\hline \#11 & Add & Search radiography & $9,10,866$ & 12:09:41 \\
\hline \#12 & Add & Search dental digital radiography & 2,506 & 12:10:08 \\
\hline$\# 13$ & Add & Search dental panoramic radiography & 3,889 & 12:10:24 \\
\hline \#14 & Add & Search cone-beam computed tomography endodontics & 292 & 12:10:38 \\
\hline \#15 & Add & Search periapical healing & 1,089 & 12:10:59 \\
\hline$\# 16$ & Add & Search apical healing & 1,169 & 12:11:05 \\
\hline \#17 & Add & Search periapical status & 412 & 12:11:20 \\
\hline$\# 18$ & Add & Search periapical index scoring system & 10 & 12:11:37 \\
\hline$\# 19$ & Add & Search orstavik periapical index & 18 & 12:11:48 \\
\hline \#20 & Add & Search treatment outcome & $8,18,237$ & 12:12:02 \\
\hline \#21 & Add & Search endodontic treatment outcome & 980 & 12:12:11 \\
\hline \#22 & Add & $\begin{array}{l}\text { Search }(((((((\text { endodontics) OR apical periodontitis) OR chronic apical periodontitis) OR } \\
\text { periapical periodontitis) OR apical lesion) OR periapical disease) OR root canal therapy) OR } \\
\text { root filled teeth) OR in vivo }\end{array}$ & $6,89,663$ & 12:12:45 \\
\hline$\# 23$ & Add & $\begin{array}{l}\text { Search ((dental digital radiography) OR dental panoramic radiography) OR cone beam } \\
\text { computed tomography endodontics }\end{array}$ & 6,230 & 12:13:07 \\
\hline 4 & Add & $\begin{array}{l}\text { Search (((((periapical healing) OR apical healing) OR periapical status) OR periapical index } \\
\text { scoring system) OR orstavik periapical index) OR endodontic treatment outcome }\end{array}$ & 2,990 & 12:13:35 \\
\hline \#25 & Add & $\begin{array}{l}\text { Search }(((((((((((\text { endodontics) OR apical periodontitis) OR chronic apical periodontitis) OR } \\
\text { periapical periodontitis) OR apical lesion) OR periapical disease) OR root canal therapy) OR } \\
\text { root filled teeth) OR in vivo)) AND (((dental digital radiography) OR dental panoramic } \\
\text { radiography) OR cone beam computed tomography endodontics)) AND ((((((periapical } \\
\text { healing) OR apical healing) OR periapical status) OR periapical index scoring system) OR } \\
\text { orstavik periapical index) OR endodontic treatment outcome)) AND periapical radiography }\end{array}$ & 104 & 12:14:04 \\
\hline
\end{tabular}

TABLE 5: Search strategies

\section{Additional Information}

\section{Disclosures}

Conflicts of interest: In compliance with the ICMJE uniform disclosure form, all authors declare the following: Payment/services info: All authors have declared that no financial support was received from any organization for the submitted work. Financial relationships: All authors have declared that they have 
no financial relationships at present or within the previous three years with any organizations that might have an interest in the submitted work. Other relationships: All authors have declared that there are no other relationships or activities that could appear to have influenced the submitted work.

\section{References}

1. Ørstavik D, Kerekes K, Eriksen HM: The periapical index: a scoring system for radiographic assessment of apical periodontitis. Endod Dent Traumatol. 1986, 2:20-34. 10.1111/j.1600-9657.1986.tb00119.x

2. Lin LM, Skribner JE, Gaengler P: Factors associated with endodontic treatment failures . J Endod. 1992, 18:625-7. 10.1016/S0099-2399(06)81335-X

3. Ng YL, Mann V, Gulabivala K: Outcome of secondary root canal treatment: a systematic review of the literature. Int Endod J. 2008, 41:1026-46. 10.1111/j.1365-2591.2008.01484.x

4. Nair PNR, Sjögren U, Figdor D, Sundqvist G: Persistent periapical radiolucencies of root-filled human teeth, failed endodontic treatments, and periapical scars. Oral Surg Oral Med Oral Pathol Oral Radiol Endod. 1999 87:617-27. 10.1016/s1079-2104(99)70145-9

5. van der Stelt PF: Experimentally produced bone lesions. Oral Surg Oral Med Oral Pathol. 1985, 59:306-12. 10.1016/0030-4220(85)90172-0

6. Demiralp KÖ, Kamburoğlu K, Güngör K, Yüksel S, Demiralp G, Uçok O: Assessment of endodontically treated teeth by using different radiographic methods: an ex vivo comparison between CBCT and other radiographic techniques. Imaging Sci Dent. 2012, 42:129-37. 10.5624/isd.2012.42.3.129

7. White SC, Atchison KA, Hewlett ER, Flack VF: Efficacy of FDA guidelines for prescribing radiographs to detect dental and intraosseous conditions. Oral Surg Oral Med Oral Pathol Oral Radiol Endod. 1995, 80:10814. 10.1016/s1079-2104(95)80026-3

8. Nakata K, Naitoh M, Izumi M, Inamoto K, Ariji E, Nakamura H: Effectiveness of dental computed tomography in diagnostic imaging of periradicular lesion of each root of a multirooted tooth: a case report. J Endod. 2006, 32:583-7. 10.1016/i.joen.2005.09.004

9. Forsberg J, Halse A: Radiographic simulation of a periapical lesion comparing the paralleling and the bisecting-angle techniques. Int Endod J. 1994, 27:133-8. 10.1111/j.1365-2591.1994.tb00242.x

10. Goldman M, Pearson AH, Darzenta N: Reliability of radiographic interpretations. Oral Surg Oral Med Oral Pathol. 1974, 38:287-93. 10.1016/0030-4220(74)90070-x

11. Huumonen S, Ørstavik D: Radiological aspects of apical periodontitis . Endod Top. 2002, 1:3-25. 10.1034/j.1601-1546.2002.10102.x

12. Whiting P, Rutjes AW, Reitsma JB, Bossuyt PM, Kleijnen J: The development of QUADAS: a tool for the quality assessment of studies of diagnostic accuracy included in systematic reviews. BMC Med Res Methodol. 2003, 3:25. Accessed: April 18, 2020: https://www.ncbi.nlm.nih.gov/pubmed/14606960. 10.1186/1471-2288-3-25

13. Lofthag-Hansen S, Huumonen S, Gröndahl K, Gröndahl HG: Limited cone-beam CT and intraoral radiography for the diagnosis of periapical pathology. Oral Surg Oral Med Oral Pathol Oral Radiol Endod. 2007, 103:114-9. 10.1016/j.tripleo.2006.01.001

14. Estrela C, Bueno MR, Leles CR, Azevedo B, Azevedo JR: Accuracy of cone beam computed tomography and panoramic and periapical radiography for detection of apical periodontitis. J Endod. 2008, 34:273-9. 10.1016/j.joen.2007.11.023

15. Estrela C, Bueno MR, Azevedo BC, Azevedo JR, Pécora JD: A new periapical index based on cone beam computed tomography. J Endod. 2008, 34:1325-31. 10.1016/j.joen.2008.08.013

16. Patel S, Wilson R, Dawood A, Mannocci F: The detection of periapical pathosis using periapical radiography and cone beam computed tomography - part 1: pre-operative status. Int Endod J. 2012, 45:702-10. 10.1111/j.1365-2591.2011.01989.x

17. Abella F, Patel S, Duran-Sindreu F, Mercadé M, Bueno R, Roig M: Evaluating the periapical status of teeth with irreversible pulpitis by using cone-beam computed tomography scanning and periapical radiographs. J Endod. 2012, 38:1588-91. 10.1016/j.joen.2012.09.003

18. Kaya S, Yavuz I, Uysal I, Akkuş Z: Measuring bone density in healing periapical lesions by using cone beam computed tomography: a clinical investigation. J Endod. 2012, 38:28-31. 10.1016/j.joen.2011.09.032

19. Gumru B, Tarcin B, Pekiner FN, Ozbayrak S: Retrospective radiological assessment of root canal treatment in young permanent dentition in a Turkish subpopulation. Int Endod J. 2011, 44:850-6. 10.1111/j.13652591.2011.01894.x

20. Ríos-Santos JV, Ridao-Sacie C, Bullón P, Fernández-Palacín A, Segura-Egea JJ: Assessment of periapical status: a comparative study using film-based periapical radiographs and digital panoramic images. Med Oral Patol Oral Cir Bucal. 2010, 15:e952-6. 10.4317/medoral.15.e952

21. Raghav N, Reddy SS, Giridhar AG, et al.: Comparison of the efficacy of conventional radiography, digital radiography, and ultrasound in diagnosing periapical lesions. Oral Surg Oral Med Oral Pathol Oral Radiol Endod. 2010, 110:379-85. 10.1016/j.tripleo.2010.04.039

22. Levin MD, Mischenko A: Limited field cone beam computed tomography: evaluation of endodontic healing in three cases. Alpha Omegan. 2010, 103:141-5. 10.1016/j.aodf.2010.10.005

23. Liang YH, Li G, Wesselink PR, Wu MK: Endodontic outcome predictors identified with periapical radiographs and cone-beam computed tomography scans. J Endod. 2011, 37:326-31. 10.1016/j.joen.2010.11.032

24. Ridao-Sacie C, Segura-Egea JJ, Fernández-Palacín A, Bullón-Fernández P, Ríos-Santos JV: Radiologica assessment of periapical status using the periapical index: comparison of periapical radiography and digital panoramic radiography. Int Endod J. 2007, 40:433-40. 10.1111/j.1365-2591.2007.01233.x

25. Yoshioka T, Villegas J, Kobayashi C, Suda H: Radiographic evaluation of root canal multiplicity in mandibular first premolars. J Endod. 2004, 30:73-4. 10.1097/00004770-200402000-00002

26. Delano EO, Ludlow JB, Ørstavik D, Tyndall D, Trope M: Comparison between PAI and quantitative digital radiographic assessment of apical healing after endodontic treatment. Oral Surg Oral Med Oral Pathol Oral Radiol Endod. 2001, 92:108-15. 10.1067/moe.2001.115466

27. Molander B, Ahlqwist M, Gröndahl HG: Panoramic and restrictive intraoral radiography in comprehensive 


\section{Cureus}

oral radiographic diagnosis. Eur J Oral Sci. 1995, 103:191-8. 10.1111/j.1600-0722.1995.tb00159.x

28. Rohlin M, Kullendorff B, Ahlqwist M, Henrikson CO, Hollender L, Stenström B: Comparison between panoramic and periapical radiography in the diagnosis of periapical bone lesions. Dentomaxillofac Radiol. 1989, 18:151-5. 10.1259/dmfr.18.4.2640445 